Bond University

Research Repository

\title{
Load Carriage for Female Military Personnel
}

Orr, Rob Marc; Pope, Rodney; O'Shea, Simone; Knapik, Joseph

Published in:

Strength and Conditioning Journal

DOI:

10.1519/SSC.0000000000000514

Licence:

Other

Link to output in Bond University research repository.

Recommended citation(APA):

Orr, R. M., Pope, R., O'Shea, S., \& Knapik, J. (2020). Load Carriage for Female Military Personnel. Strength and Conditioning Journal, 42(4), 50-58. https://doi.org/10.1519/SSC.0000000000000514

\section{General rights}

Copyright and moral rights for the publications made accessible in the public portal are retained by the authors and/or other copyright owners and it is a condition of accessing publications that users recognise and abide by the legal requirements associated with these rights.

For more information, or if you believe that this document breaches copyright, please contact the Bond University research repository coordinator. 


\section{Load Carriage for Female Military Personnel}

${ }^{1,2}$ Dr Robin M. Orr, ${ }^{1,3}$ Dr Rodney P. Pope, ${ }^{3}$ Dr Simone O’Shea $\&{ }^{4}$ Dr Joseph J. Knapik

${ }^{1}$ Tactical Research Unit, Bond University

${ }^{2}$ Faculty of Health Sciences and Medicine, Bond University

${ }^{3}$ Faculty of Science, Charles Sturt University

${ }^{4}$ US Army Research Institute of Environmental Medicine; Henry M Jackson Foundation for the Advancement of Military Medicine

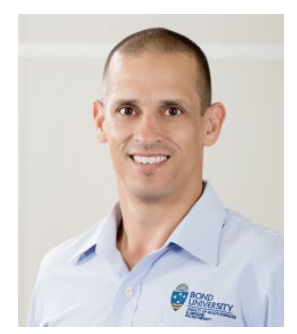

Associate Professor Robin Orr (PhD, MPhty, BFET, TSAC-F) - Corresponding Author: Bond Institute of Health and Sport

Bond University

Gold Coast, QLD 4226

Ph: 61 (0) 755954448

Mob: 61 (0) 468646027 Email: rorr@bond.edu.au

Current positions: Rob is an Associate Professor of Physiotherapy at Bond University and Lead of the Bond University Tactical Research Unit, a Human Performance Officer in the Australian Army Reserve and Editor of the Tactical Strength and Conditioning TSAC Report.

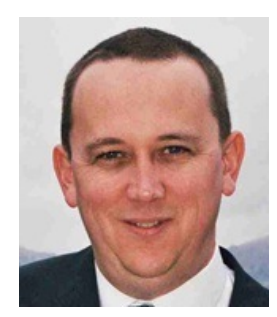

Professor Rodney Pope (PhD, BAppSc(Phty), GradDipPsychStud)

Faculty of Science

Charles Sturt University

Albury, NSW 2640

Ph: 61 (0) $260519247 \quad$ Mob: 61 (0) $403417564 \quad$ Email: rpope@csu.edu.au

Current position: Rod is a Professor of Physiotherapy at Charles Sturt University and an Honorary Adjunct Professor with the Bond University Tactical Research Unit.

This is a non-final version of an article published in final form in: 


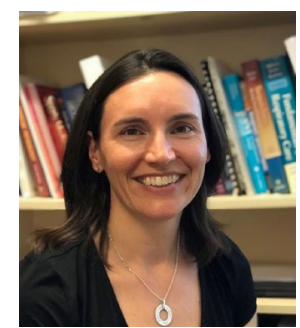

Dr Simone O'Shea (PhD, BPhysio(Hons))

Faculty of Science

Charles Sturt University

Albury, NSW 2640

Ph: 61 (0) $260519234 \quad$ Mob: 61 (0)410616813Ｅmail: $\underline{\text { soconnor@csu.edu.au }}$

Current position: Simone is a Lecturer in Physiotherapy at Charles Sturt University and also works clinically as a Physiotherapist for women during the childbearing.

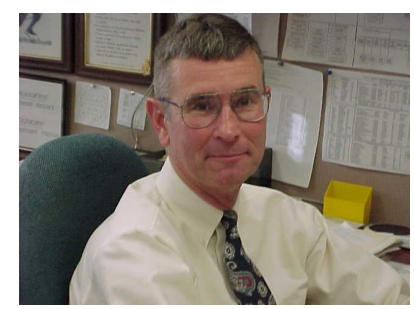

Joseph J Knapik (ScD, CSCS, FACSM)

Senior Epidemiologist/Research Physiologist

US Army Research Institute of Environmental Medicine

Natick Massuettes, USA

Henry M Jackson Foundation for the Advancement of Military Medicine

Bethesda, Maryland, USA

Current Position: Joe is a Senior Epidemiologist/Research Physiologist at the US Army Research Institute of Environmental Medicine, and Henry M Jackson Foundation for the Advancement of Military Medicine, and Honorary Adjunct Professor with the Bond University Tactical Research Unit. 


\title{
Load Carriage for Female Military Personnel
}

\begin{abstract}
This paper reviews the physiological, biomechanical, and health impacts of load carriage on the female soldier and includes issues impacting on the female athlete and hence female soldier. Physiological factors, (e.g., mass, strength, and aerobic endurance), and biomechanical factors (e.g., forward trunk lean, and step length) have the potential to increase the energy cost of load carriage and injury risk. Optimal load carriage conditioning guidelines are presented while considering issues specific to the female soldier, including the female athlete triad and pelvic floor muscle dysfunction which can likewise reduce performance and increase injury risk.
\end{abstract}

Key words: tactical athlete; soldier; armed forces; injury; ruck march; female athlete. 


\section{LOAD CARRIAGE AND THE FEMALE SOLDIER}

\section{INTRODUCTION}

With the removal of sex restrictions from military combat trades (65), the numbers of women serving in defense forces are growing (19) and there has been an increase in female soldiers engaged in combat (9), receiving awards for combat actions (94), and becoming combat fatalities (94). While on combat operations soldiers, regardless of sex, are required to carry heavy loads; loads that history would indicate are increasing $(47,70)$. These carried loads include vital stores, ammunition and equipment, and can exceed $45 \mathrm{~kg}$ on combat operations $(20,75)$.

Considering these loads, females are, on average, about $13 \mathrm{~kg}$ lighter than men and have about 35\% less muscle mass (36). As such, a set combat load (e.g. $45 \mathrm{~kg}$ ) carried by a female soldier could equate to a much higher load relative to body or muscle mass when compared to their male counterpart. Earlier research by Orr et al. (75), prior to the removal of sex restrictions from combat roles, found that female soldiers carried similar relative loads $(\%$ of body mass) when compare to male soldiers, but significantly lighter absolute loads. With the loads required to remain extant for combat operations regardless of sex (65), the removal of sex restrictions will likely lead to an increased absolute load for female soldiers (commensurate with those carried by male soldiers) and hence a greater relative load. This supposition is supported by research in law enforcement (4). A study in U.S. law enforcement officers by Baran et al. (4) found that, while female officers wore and carried similar absolute loads to those of male officers, female officers wore and carried significantly heavier relative loads. 
With combat loads increasing, the numbers of female soldiers exposed to these heavy loads increasing, and a potential for these loads to be relatively greater for female soldiers it is of no surprise that load carriage is considered one of the major physical challenges for female soldiers seeking to demonstrate competence in combat arms professions (65). There are significant differences between men and women in average muscular and cardiovascular fitness and heavier combat loads are likely associated with increased risk of injury in female soldiers in particular. Given that physiological differences between women and men are taken into consideration when training athletes (88), similar considerations should be given to female soldiers who are required to carry, and be conditioned to carry, heavy loads during their military service.

The purpose of this paper is to review the physiological, biomechanical, and injuries risk factors associated with load carriage on the female soldier. The paper will also recommend conditioning approaches and sex-specific issues acknowledged as impacting on the female athlete and soldier in order to make recommendations regarding approaches to conditioning of female soldiers for load carriage.

\section{LOAD CARRIAGE AND ITS PHYSIOLOGICAL IMPACT}

The greater the load carried, the greater the energy cost of standing and moving $(11,78,85)$. With female soldiers wearing and carrying combat loads, whether standing at a vehicle check point or patrolling, the weight of their load is going to extract a physiological cost, a cost which may be greater, on average, than those imparted on male soldiers $(6,32,35)$. Apart from the load weight, the position of the load on the body can influence the energy costs of load carriage $(68,96)$ with average energy costs differing between sexes $(55)$. For example, loads carried in a split between the front and back (double pack) have been found to be more 
efficient than loads carried exclusively on the back $(17,55)$ these efficiencies have been observed to be greater in female soldiers (55). Noting that differences between the sexes in average energy costs may exist, cardiovascular fitness and muscular strength are, regardless of sex, important fitness components associated with load carriage ability $(86,89)$.

On average, females have lower mean aerobic and anaerobic capacity, and lower strength in both the general population (36) and in samples of military women (1). As such, female participants have been found to typically work at a higher percentage of their maximum aerobic capacity than their male counterparts when carrying the same absolute loads at the same intensity (e.g. same speed and gradient) $(6,32,35)$. These findings are supported by research showing that female load carriage participants, on average, walk at a slower pace than their male counterparts when walking at a self-determine pace to complete a given distance with a set load $(32,35)$ In one study $(32)$, men walking at a self-paced marching speed were $21 \%$ faster than women regardless of load carried (range 18-36 kg).

When it comes to strength, both absolute and relative strength are important to load carriage performance (86). Absolute strength is, to some extent, related to body mass, with heavier men and women tending to have greater absolute strength (24) and perform better in military and load carriage tasks $(29,31,77)$. For example, Patterson et al. (77) found that taller, heavier, stronger females with a slightly greater aerobic capacity were more likely to successfully complete a $15 \mathrm{~km}$ march $(5.5 \mathrm{~km} / \mathrm{h}, 35 \mathrm{~kg}$ load $)$ than their shorter, lighter, and lower strength counterparts. Thus, for the female soldier, it appears that being heavier and stronger with a greater aerobic capacity may be beneficial during load carriage tasks. Importantly, Robinson et al. (86), investigated the load carriage performance of male specialist tactical response police, and found that while absolute strength (maximum load lifted in a squat, deadlift, bench press and shoulder press) was significantly related to higher 
load carriage performance, relative strength (the absolute strength measures divided by the lifter's body mass) correlations were stronger. As such, with the relative load considerably heavier for the average female soldier, the need for female soldiers to increase relative strength may be of greater importance than increases in absolute strength alone.

\section{LOAD CARRIAGE AND ITS BIOMECHANICAL IMPACT}

As the carried load mass increases, the body posture and movements of the load carrier are altered. Soldiers have been found to increase forward trunk lean as backpack loads increased $(3,23,80)$, with this postural response greater in female soldiers $(50,90)$. This postural response alters biomechanics further up the spine, with the head adopting a more forward posture (3), and down the spine, with the hips adopting an increased bend and concomitant increase in activation of lower back and pelvis extensor muscles (90). Increasing load also brings with it changes in spinal curvatures in both females and males, with loads as light as 8 $\mathrm{kg}(23,61,69)$. Higher load mass, in concert with spinal curvature changes and increased forward lean, may increase the risk of back injury.

Load carriage tasks may also elicit different spatiotemporal responses according to sex. On average, females are of shorter stature and as the weight of a given carried load increases, female stride lengths tend to decrease, while male stride lengths may stay relatively unchanged $(56,59)$. Consequently, with gait speed the product of stride length and stride frequency, the shorter stride lengths can require females to employ a higher mean stride frequency to maintain a given pace, thereby increasing loading cycles. In some military situations the option to increase stride frequency is removed, such as when soldiers are required to maintain a given cadence or 'keep in step' (90). This practice, by restricting the ability of females (and shorter personnel) to adjust stride frequency, forces stride lengths to 
increase to maintain a set speed. This increase in stride length can lead to over striding and increase the risk of lower extremity injury $(81,90)$. As an example, adaptive over striding can place additional shearing stress on the pelvis, leading to stress reactions or stress fractures in the pelvic bones (81).

However, not all research show changes in spatiotemporal parameters when comparing the sexes $(50,91)$. When men and women are matched on height and weight, there are no significant spatiotemporal differences between the sexes (91). This suggests that body size, and not sex per se, accounts for these differences.

\section{INJURIES ASSOCIATED WITH LOAD CARRIAGE}

Load carriage places strain on the body by increasing the mass supported and carried on the musculoskeletal system $(30,80)$. On this basis, load carriage tasks have the potential to cause acute and overuse injuries. During military load carriage events military personnel have presented with blisters, musculoskeletal pain, stress fractures, and neuropathies (like brachial plexus palsy), as well as other injury types $(40,45,46,74,76)$.

Injuries to the lower back are common during or following load carriage tasks (48) and can be a leading cause of failure to complete a load carriage event (48). A study investigating differences in load carriage injuries by sex found that female and male soldiers suffered similar rates of lower back injuries (IRR $=1.26 ; 95 \%$ CI 0.67 to 2.37 ), but female soldiers tended towards more severe injuries ( $I R R=2.40 ; 95 \%$ CI 0.98 to 5.88$)$ (74). This potential for more severe injuries may be explained by the aforementioned greater relative loading and greater forward lean in female soldiers when carrying loads, the impacts of which lend to greater extensor muscle activation to counterbalance these changes and more stress through 
the lower back. Following lower back injuries as the leading site of injuries in both sexes, Orr et al. (74) found that the foot was the second leading site of injuries in female soldiers, as opposed to the ankle, which was the second leading site in male soldiers. These results suggest potential differences in both severity and sites of load carriage injuries between sexes.

One civilian study examined injuries experienced by recreational hikers on a 23-day Outward Bound training course that involved extensive backpacking in addition to rock climbing and development of basic camping skills (98). One or more injuries was reported by $85 \%$ of the men $(n=216)$ and $94 \%$ of women $(n=127)(p<0.05)$. While instructive, these recreational hikers carried lighter loads than are typical of the military and the data were from self-report surveys, which may suffer from recall bias and tend to underestimate the actual injuries experienced.

\section{CONDITIONING FOR LOAD CARRIAGE}

Low levels of fitness are associated with an increased risk of injury during both general military training $(41,82)$ and load carriage activities, specifically (39). Therefore, physical conditioning to increase fitness levels may constitute one means of limiting load carriage injuries (73). Noting that cardiovascular fitness and strength are important characteristics for successful load carriage, conditioning programs that address both of these conditioning requirements have been found to improve load carriage performance to a greater extent than programs which address just one of these requirements in isolation (44).

The most effective method for improving load carriage performance appears to be walking with loads $(44,73)$. In one study $(86)$, time to complete one load carriage event was strongly correlated with time to complete a future load carriage event up to 12 months later $(\mathrm{r}=.840)$. 
Nonetheless, also related to load carriage performance were aerobic fitness $(r=-.709)$, relative strength measures ( $\mathrm{r}=-.294$ to -.512$)$ and absolute strength measures ( $\mathrm{r}=-.248$ to -.439$)(86)$. This finding aligns with the principle of specificity, whereby training specific to the activity has the potential to best optimize performance of the activity (27). As such, load carriage training, be it as a physical training session or part of field craft, has the greatest potential to increase load carriage performance $(44,73)$. However, given that load carriage training can itself be a mechanism of injury, the frequency of load carriage training events should be applied cautiously, with a load carriage specific session conducted every seven to 10 days (42, 44,73 ). In addition, the training factors involved in load carriage training, including distance, duration, speed of march and terrain (type and grade) need to be applied progressively, with sufficient periods of recovery and using a periodized training approach implemented over a minimum of 6 months (65). Consideration should also be given to other musculoskeletal loading that may be experienced by soldiers as part of their daily program (71). For example, recruits in basic training were found to cover distances of 7.5 to $11 \mathrm{~km}(43,72)$ each day on foot, exclusive of any load carriage conditioning, and this needs to be taken into account to avoid overtraining (71).

Any resistance training employed to improve load carriage in female soldiers should focus on both strength and power, since these fitness components have been associated with higher levels of performance on simulated military tasks (box lifts, loaded runs, 30-m sprint, zig-zag run, casualty drag) undertaken during load carriage $(49,57,65)$. As such, the resistance training should focus on progressively increasing the load and performing a 3 to 8 repetition maximum, as skill levels allow, and should involve a specific focus on upper body conditioning (65), which is generally lower in females as opposed to males (52) and strongly correlated to load carriage performance $(57,86)$. High intensity, low volume resistance training may also be of value by improving aerobic and anaerobic capacity (65). Furthermore, 
this form of conditioning meets with recommendations to prepare soldiers for an anerobic battle field, in which some elements of battle are more explosive and of shorter duration (e.g. vehicle counter ambush drill) than typical long patrols and engagements (57).

\section{OTHER CONSIDERATIONS FOR FEMALE SOLDIERS}

Consideration also needs to be given to sex-specific concerns identified as impacting on female athletes; concerns like the female athlete triad, poor nutrition and hydration practices, urinary incontinence (UI) and pelvic floor muscle function. These additional considerations are further discussed below.

\section{The female athlete triad}

The term "female athlete triad", representing eating disorders, amenorrhea, and osteoporosis, was first coined in a special American College of Sports Medicine (ASCM) conference in 1992 to represent three factors associated with female athlete injury risk (2). In a 2007 update the ACSM amended the female athlete triad to emphasize low energy availability, menstrual dysfunction and low bone mineral density, with these factors represented along a spectrum from healthy to dysfunctional (64). Alone, or in combination, these three factors are thought to pose a significant threat to physically active women (64) with the female athlete not needing to present with all three components of the syndrome to be diagnosed with the condition (60).

Low energy availability can be caused by poor nutritional intake or excessive energy expenditure, above what the body can facilitate (60). With the estimates of prevalence of eating disorders in the military equal to or above those for the general population and ranging 
from 5 to $8 \%(5,53,54)$, the potential for eating disorders deserves consideration given that female service members may purposefully restrict energy intake, self-induce vomiting, take laxatives and diuretics (amongst other behaviors) in order to meet body weight requirements (5). However, disordered eating behaviors are not the only risk factor in a female soldier population, with poor nutritional intake and excessive energy expenditure potential consequences of being in the military. On exercise or deployment, where nutritional intake may come from combat ration packs, female soldiers may simply not consume sufficient energy (38) as soldiers can often discard portions of their ration packs due to personal taste and thus fail to meet required energy intakes (8). Conversely, the physical demands of field exercises, which include load carriage, can increase energy requirements (7). This paradigm of insufficient energy intake to sustain bodily health, once the requirements of the physical demands of exercise and sport (in this case military training) are taken into account, is not new. In 2014, the International Olympic Committee created the phrase Relative Energy Deficiency in Sport (RED-S) to represent this potential for energy deficiency which could occur as a result of a high volume of physical activity (58). While there is some controversy regarding this term in association with the female athlete triad (63), the divide between intake and expenditure may be exacerbated by the nature of military training and deployments. This divide not only places the female soldier at greater risk in relation to this component of the female athlete triad, but also the poor reproductive health component, which is impacted by energy intake (60).

By definition, amenorrhea is a dysfunction of the menstrual cycle which leads to an absence of a regular menstrual cycle (37) and can be either primary (the absence of menarche over the age of 15) or secondary (the cessation of menses for three consecutive cycles post menarche) (60). Amenorrhea can be caused by several factors prevalent in female military soldiers, 
including; high intensity physical exercise (10), the stress of war (37), and deliberate menstrual suppression during deployment (97).

With the cessation of menstruation, hormone balances, like that of the hormone estrogen, are disrupted (60). In an estrogen-deficient state, bone mineral density is decreased (60) and this can in turn increase the risk of stress fractures in military personnel (83). In a study of both female high school athletes (84) and female military recruits (83), female athletes and soldiers who reported being amenorrhoeic were found to have around a threefold increase in the risk of musculoskeletal injury (84) and lower-extremity stress fracture (83) risk. On the other hand, a past history of amenorrhea was not found to be related to subsequent stress fracture risk (13) suggesting that stress fracture risk may be mitigated by the restoration of eumenorrhea following a period of menstrual dysfunction,

Osteoporosis is an increase in the porosity of bone caused by a decrease in bone mineral density (79). Although osteoporosis is more common in post-menopausal women, athletes suffering from reduced energy intake (and, as such, reduced calcium, vitamin D and protein consumption (60)) and menstrual disturbances have decreased bone protection (64). As noted above, this situation is associated with an increased risk of musculoskeletal injury and fracture $(83,84)$

When considering the three components of the female triad and its impact on the female soldier, the risk imparted by load carriage is of concern. Load carriage increases the energy costs of a given activity and as such may contribute to low energy balance. This energy balance can be further impacted by the female soldier's restriction to eating only combat rations or the intentional removal of food and water to reduce load weight. The physical training requirements to prepare female soldiers to carry loads can likewise increase energy 
deficits, as well as leading to amenorrhea given the training intensity. Finally, load carriage itself is associated with increased skeletal loading and a likely cause of musculoskeletal injuries and fractures, the risks of which can be increased by amenorrhea and low bone mineral density. As such, load carriage has the potential to exacerbate, if not induce, the female athlete triad and its adverse effects in female soldiers.

On this basis, an aim of any load carriage conditioning program should be to prevent the female athlete triad from occurring. This can be done through education about the triad itself and potential consequences (60). Food availability, notably with calcium and vitamin D, should be optimized, especially during periods of increased energy utilization, to mitigate a low energy balance (60). Finally, the conditioning process itself should be progressive and structured and include periods of de-loading or 'orthopedic holidays' to allow for bone stress recovery $(73,87)$.

\section{Load carriage and pelvic floor function}

Pelvic floor dysfunction is an umbrella term encompassing a wide variety of symptoms, such as urinary incontinence, bladder storage or voiding issues, lower urinary tract infection, pelvic organ prolapse, anorectal dysfunction, sexual dysfunction and pelvic pain (34). Pelvic floor dysfunction more commonly affects females more than males (33), with moderate to severe symptoms of urinary incontinence, pelvic organ prolapse or fecal incontinence reported by one quarter of US females (67). Although age, obesity, gynecological surgery and parity are all considered key risk factors for female pelvic floor dysfunction $(66,99)$, participating in regular lifting, load carriage and higher impact physical activity has also been implicated (66). Urinary incontinence is commonly reported by females during physical activity (prevalence range $15-80 \%$ ), with higher impact activities such as repetitive jumping and higher training 
loads associated with greater urinary incontinence (66). Occupational tasks have also been implicated in female urinary incontinence and pelvic organ prolapse, with more physically demanding work tasks associated with increased pelvic floor symptoms $(66,100)$.

Females in military occupations may be at an increased risk of pelvic floor dysfunction, given that strenuous physical activity and load carriage are commonly required. Despite this, pelvic floor function has received little attention in this population. Davis et al. (18) conducted a self-administered questionnaire of 563 active duty female soldiers and found that $30 \%$ experienced urinary incontinence to a degree that was considered a social or hygienic problem. Increasing age and parity were key risk factors, and physical training and field exercises were the main aggravating activities. Furthermore, female personnel who worked as fuel technicians, cooks or in supply roles reported episodes of urinary incontinence more frequently (18). In another self-report cross-sectional survey, $26 \%$ of female active duty US Air Force crew reported urinary incontinence, with age and parity also identified as key risk factors (22). However, episodes of incontinence mainly occurred off-duty (89\%), compared with being on-duty but not flying (31\%) and while flying (18\%). Considering this, the flying of high performance aircraft was not associated with an increased risk of urinary incontinence (22). Nulliparous paratrooper trainees were found to be significantly more likely to have a stage II prolapse and worsening of their pelvic organ support post-training than those engaged with other areas of training (51) and this finding was attributed to the large forces transmitted to the pelvis from jumps during training.

The proposed mechanism contributing to pelvic floor dysfunction from high impact physical activity and load carriage is increases in intra-abdominal pressure, which are thought to contribute to spinal stabilization, but also exert a concomitant repetitive downward force on the pelvic floor (93). An increasing number of recent studies have started to examine intra- 
abdominal pressure during a variety of lifting, load carriage and physical activities. Intraabdominal pressure has been shown to be influenced by the weight lifted and the mode of lifting (26), and the pace at which the activity is undertaken (12). Significant amounts of individual variation have also been found within activities $(25,92)$, suggesting that the impacts of repetitive loading on the pelvic floor may vary considerably. The effect of physical activity and load carriage on pelvic floor function remains unclear, and the findings of available studies $(12,25,26,92)$ may have limited applicability to women in the military context because the types, durations, and intensities of the loads investigated were typically much lower than are likely to be experienced by female soldiers.

While there is limited research on the prevalence of pelvic floor dysfunction in female military personnel, its presence may have a detrimental effect on occupational performance, and physical and emotional well-being $(15,18)$. One-third of female soldiers with urinary incontinence reported that they needed to modify or adapt their training or duties to manage the condition (18). Of concern is that common self-management strategies such as delayed or timed voiding, fluid restriction, and the use pads, tampons or pessaries $(14,18,95)$ may increase the risks of heat-related illness and urinary tract infections, particularly in austere deployment or field settings.

Given the requirement for female soldiers to carry loads, strategies for preventing and managing pelvic floor dysfunction warrant consideration. Specific pelvic floor muscle training has a growing body of evidence supporting its role as a first line conservative management strategy for female urinary incontinence (21), and it may also influence the severity of symptoms in pelvic organ prolapse (28). Despite the developing body of research examining the role of pelvic floor muscle training in the prevention of pelvic floor dysfunction, there is evidence to suggest that more general regular exercise and physical 
conditioning do not develop greater strength in the pelvic floor muscles $(16,62)$. These findings support the need for specific pelvic floor muscle education and training, in addition to a load carriage conditioning program, particularly in female soldiers where the relative loads on the pelvic floor may be increased.

\section{SUMMARY}

The increased potential for female soldiers to now be deployed in direct combat roles means that more female soldiers may be exposed to the heavy load carriage requirements associated with combat trades. With female soldiers on average being lighter and possessing lower strength and aerobic fitness levels than their male counterparts, the energy costs imparted by load carriage as well as severity of injury can be higher than those impacting on their male counterparts when carrying the same loads. Biomechanical differences, like stride length and increased forward trunk lean, also have the propensity to increase both the energy cost of completing a load carriage task and the potential for injury in female soldiers. To prepare female soldiers to carry heavy loads and mitigate the risk of injury, progressive load carriage specific conditioning, inclusive of dedicated strength training, is needed. However, female athlete specific concerns associated with physical conditioning and heavy occupational physical activity, like the female athlete triad and pelvic floor dysfunction, must be considered.

\section{CONCLUSIONS}

Female soldiers are required to carry heavy loads that may be relatively heavier than those of their male counterparts due to their generally lower body mass. These loads impart an energy cost and can increase injury risk, which due to physiological (e.g. lower average stature, strength, and aerobic capacity) and biomechanical factors (e.g., greater average stride length and forward trunk lean) may be higher in female soldiers. Research evidence presented in this 
paper details physical conditioning strategies to enhance load carriage performance and reduce associated risks specific to female soldiers. While some of this evidence is drawn from research in the context of female athletes, evidence from research in the military context is predominant. Noting the removal of sex restrictions for entry into combat trades, it is timely that the implementation of appropriate strategies to enhance load carriage performance and reduce associated risks among female soldiers is further explored.

\section{REFERENCES}

1. Allison KF, Keenan KA, Sell TC, Abt JP, Nagai T, Deluzio J, McGrail M, and Lephart SM. Musculoskeletal, biomechanical, and physiological gender differences in the US military. US Army Medical Department Journal 2015: 12-22, 2015.

2. American College of Sports Medicine. The Female Athlete Triad. Position Stand 25, 1997.

3. Attwells R, Birrell SA, Hooper RH, and Mansfield NJ. Influence of carrying heavy loads on soldier's posture, movements and gait. Ergonomics 49: 1527-1537, 2006.

4. Baran K, Dulla J, Orr R, Dawes J, and Pope R. Duty loads carried by the LA sheriff's department deputies. J Strength Cond Res 26: 34-38, 2018.

5. Bartlett BA and Mitchell KS. Eating disorders in military and veteran men and women: A systematic review. Int J Eat Disord 48: 1057-1069, 2015.

6. Bhambhani Y and Maikala R. Gender differences during treadmill walking with graded loads: biomechanical and physiological comparisons. Eur J Appl Physiol 81: 75-83, 2000 .

7. Booth CK. Not eating enough the trouble with combat rations. Revue internationale des services de santé des forces armées, 76: 93-96, 2013.

8. Booth CK. Combat rations and military performance-do soldiers on active service eat enough? Asia Pacific Journal of Clinical Nutrition 12: S2, 2003.

9. Burnes T and Army War Coll Carlisle Barracks PA. Contributions of Women to US Combat Operations. Army War College Carlisle Barracks PA, 2008.

10. Castelo-Branco C, Reina F, Montivero AD, Colodron M, and Vanrell JA. Influence of high-intensity training and of dietetic and anthropometric factors on menstrual cycle disorders in ballet dancers. Gynecol Endocrinol 22: 31-35, 2006.

11. Charteris J, Scott PA, and Nottrodt JW. Metabolic and kinematic responses of African women head loaded carriers under controlled conditions of load and speed. Ergonomics 32: 1539-1550, 1989. 
12. Coleman TJ, Hamad NM, Shaw JM, Egger MJ, Hsu Y, Hitchcock R, Jin H, Choi CK, and Nygaard IE. Effects of walking speeds and carrying techniques on intra-abdominal pressure in women. Int Urogynecol J 26: 967-974, 2015.

13. Cosman F, Ruffing J, Zion M, Uhorchak J, Ralston S, Tendy S, McGuigan FE, Lindsay $\mathrm{R}$, and Nieves J. Determinants of stress fracture risk in United States Military Academy cadets. Bone 55: 359-366, 2013.

14. Criner JA. Urinary incontinence in vulnerable populations: female soldiers. Urologic Nursing 21: 120-124, 2001.

15. Criner JA. An exploratory study of the psychosocial effects of stress urinary incontinence and coping strategies among military women. PhD Dissertation. University of Texas at Austin, 2006, pp 204.

16. da Silva Borin LCM, Nunes FR, and de Oliveira Guirro EC. Assessment of pelvic floor muscle pressure in female athletes. $P M \& R$ 5: 189-193, 2013.

17. Datta SR and Ramanathan NL. Ergonomic comparison of Seven Modes of Carrying Loads on the Horizontal Plane. Ergonomics 14: 269-278, 1971.

18. Davis G, Sherman R, Wong MF, McClure G, Perez R, Hibbert M, Davis G, Sherman R, Wong MF, McClure G, Perez R, and Hibbert M. Urinary incontinence among female soldiers. Mil Med 164: 182-187, 1999.

19. Davison S. The Combat Exclusion of Women in the Military: Paternalistic Protection or Military Need? Australian Army Journal IV: 59-79, 2007.

20. Dean C, and DuPont F. The Modern Warrior's Combat Load-Dismounted Combat Operations in Afghanistan. Report from the US Army Center for Army Lessons Learned, 2003.

21. Dumoulin C, Cacciari LP, and Hay-Smith EJC. Pelvic floor muscle training versus no treatment, or inactive control treatments, for urinary incontinence in women. Cochrane Database of Systematic Reviews 4, CD005654, 2018.

22. Fischer JR, Berg, P.H. Urinary Incontinence in United States Air Force female crew. Obstet Gynecol 94: 532-536, 1999.

23. Fowler NE, Rodacki AL, and Rodacki CD. Changes in stature and spine kinematics during a loaded walking task. Gait \& Posture 23: 133-141, 2006.

24. Fuster V, Jerez A, and Ortega A. Anthropometry and strength relationship: male-female differences. Anthropologischer Anzeiger 49-56, 1998.

25. Gephart LF, Doersch KM, Reyes M, Kuehl TJ, and Danford JM. Intraabdominal pressure in women during CrossFit exercises and the effect of age and parity. Baylor University Medical Center Proceedings 31: 289-293, 2018.

26. Gerten KA, Richter HE, Wheeler TL, 2nd, Pair LS, Burgio KL, Redden DT, Varner RE, and Hibner M. Intraabdominal pressure changes associated with lifting: implications for postoperative activity restrictions. Am J Obstet Gynecol 198: 306 e301-305, 2008. 
27. Sheppard JM and Triplett NT. Program design for resistance training. In: Essentials of strength training and conditioning 4th edition. Haff, GG, and Triplett, NT, eds. Champaign, IL:Human Kinetics, 440, 2015.

28. Hagen S and Stark D. Conservative prevention and management of pelvic organ prolapse in women. Cochrane Database of Systematic Reviews 12, CD003882, 2011.

29. Harman E, Gutekunst DJ, Frykman PN, Sharp M, Nindl BC, Alemany JA, and Mello RP. Prediction of Simulated Battlefield physical performance from Field-Expedient Tests. Mil Med 173: 36-41, 2008.

30. Harman E, Han K-H, and Frykman PN. Load-speed interaction effects on the biomechanics of backpack load carriage. In: RTO Meeting Proceedings 56: Soldier Mobility: Innovations in Load Carriage System Design and Evaluation, Kingston, Canada, 27-29 June 2000. Research and Technology Organisation/North Atlantic Treaty Organization, 2001.

31. Harper WH, Knapik JJ, and de Pontbriand R. Equipment compatibility and performance of men and women during heavy load carriage. In: Proceedings of the Human Factors and Ergonomics Society 41st Annual Meeting, 1997. Los Angeles, CA: SAGE Publications, 41: 604-608, 1997.

32. Harper WH, Knapik JJ, and de Pontbriand R. Female Load-Carrying Performance. Human Research \& Engineering Directorate, Army Research Laboratory ARL-TR1176: 124, 1997.

33. Hawthorne G. Measuring incontinence in Australia. Report. Canberra: Commonwealth of Australia, 2006.

34. Haylen BT, De Ridder D, Freeman RM, Swift SE, Berghmans B, Lee J, Monga A, Petri E, Rizk DE, and Sand PK. An International Urogynecological Association (IUGA)/International Continence Society (ICS) joint report on the terminology for female pelvic floor dysfunction. Neurourol Urodyn 29: 4-20, 2010.

35. Holewijn M, Heus R, and Wammes LJA. Physiological strain due to load carrying in heavy footwear. Eur J Appl Physiol 65: 129-134, 1992.

36. Katch VL, Katch FI, and McArdle WD. Exercise physiology: nutrition, energy, and human performance. Philadelphia, PA: Lippincott Williams \& Wilkins, 2015.

37. Kaufman A. Amenorrhea. Family Medicine 118: 10-12, 2009.

38. Keep L. Health Care For Women In Mobilization and Deployment. Military Preventative Medicine: Mobilization and Deployment, Volume 1: 341-362, 2003.

39. Knapik JJ. Physiological, Biomechanical and Medical Aspects of Soldier Load Carriage. In: RTO Meeting Proceedings 56: Soldier Mobility: Innovations in Load Carriage System Design and Evaluation, Kingston, Canada, 27-29 June 2000. Research and Technology Organisation/North Atlantic Treaty Organization, 2001.

40. Knapik JJ. Injuries and injury prevention during foot marching. Journal of Special Operations Medicine 14: 131-135, 2014. 
41. Knapik JJ. The importance of physical fitness for injury prevention: Part 1. Journal of Special Operations Medicine 15: 123-127, 2015.

42. Knapik JJ, Bahrke M, Staab J, Reynolds KL, Vogel JA, and O'Connor J. Frequency of Loaded Road March Training and Performance on a Loaded Road March. T13-90. Military Performance Division US Army Research Institute of Environmental Medicine, Natick: 52, 1990.

43. Knapik JJ, Darakjy S, and Hauret KG. Ambulatory physical activity during United States army basic combat training. Int J Sports Med 28: 106-115, 2007.

44. Knapik JJ, Harman EA, Steelman RA, and Graham BS. A systematic review of the effects of physical training on load carriage performance. J Strength Cond Res 26: 585$597,2012$.

45. Knapik JJ, Reynolds K, Orr R, and Pope R. Load Carriage-Related Paresthesias (Part 1): Rucksack Palsy and Digitalgia Paresthetica. Journal of Special Operations Medicine 15: 37-42, 2016.

46. Knapik JJ, Reynolds K, Orr R, and Pope R. Load Carriage-Related Paresthesias (Part 2): Meralgia Paresthetica. Journal of Special Operations Medicine 17: 94, 2017.

47. Knapik JJ, Reynolds KL, and Harman E. Soldier load carriage: Historical, physiological, biomechanical, and medical aspects. Mil Med 169: 45-56, 2004.

48. Knapik JJ, Reynolds KL, Staab J, Vogel JA, and Jones B. Injuries associated with strenuous road marching. Mil Med 157: 64-67, 1992.

49. Kraemer W, Mazzetti S, Nindl BC, Gotshalk L, Volek J, Marx J, Dohi K, Gomez PS, Miles M, Fleck J, Newton R, and Keijo H. Effect of resistance training on women's strength/power and occupational performances. Med Sci Sports Exerc 33: 1011-1025, 2001 .

50. Krupenevich R, Rider P, Domire Z, and DeVita P. Males and females respond similarly to walking with a standardized, heavy load. Mil Med 180: 994-1000, 2015.

51. Larson WI, Yavorek, T. Pelvic prolapse and urinary incontinence in nulliparous college women in relation to paratrooper training. Int Urogynecol J 18: 769-771, 2007.

52. Laubach LL. Comparative muscular strength of men and women: a review of the literature. Aviat Space Environ Med 47: 534-542, 1976.

53. Lauder TD, Williams MV, Campbell CS, Davis G, Sherman R, Pulos E. The female athlete triad: prevalence in military women. Mil Med 164:630-5, 1999

54. Lauder TD, Williams MV, Campbell CS, Davis GD, and Sherman RA. Abnormal eating behaviors in military women. Med Sci Sports Exerc 31: 1265-1271, 1999.

55. Li SS, Chan OH, Ng T, Kam L, Ng C, Chung W, and Chow DH. Gender Differences in Energy Expenditure During Walking With Backpack and Double-Pack Loads. Human factors 61: 203-213, 2019.

56. Ling W, Houston V, Tsai YS, Chui K, and Kirk J. Women's load carriage performance using modular lightweight load-carrying equipment. Mil Med 169: 914-919, 2004. 
57. Mala J, Szivak TK, Flanagan SD, Comstock BA, Laferrier JZ, Maresh CM, and Kraemer WJ. The role of strength and power during performance of high intensity military tasks under heavy load carriage. US Army Medical Department J: 3-11, 2015.

58. Marcason W. Female athlete triad or relative energy deficiency in sports (RED-S): is there a difference? Journal of the Academy of Nutrition and Dietetics 116: 744, 2016.

59. Martin PE and Nelson RC. The effect of carried loads on the walking patterns of men and women. Ergonomics 29: 1191-1202, 1986.

60. Matzkin E, Curry EJ, and Whitlock K. Female athlete triad: past, present, and future. Journal of the American Academy of Orthopaedic Surgeons 23: 424-432, 2015.

61. Meakin JR, Smith FW, Gilbert FJ, and Aspden RM. The effect of axial load on the sagittal plane curvature of the upright human spine in vivo. J Biomech 41: 2850-2854, 2008 .

62. Middlekauff ML, Egger MJ, Nygaard IE, and Shaw JM. The impact of acute and chronic strenuous exercise on pelvic floor muscle strength and support in nulliparous healthy women. Am J Obstet Gynecol 215: 316. e311-316. e317, 2016.

63. Mountjoy M, Sundgot-Borgen J, Burke L, Carter S, Constantini N, Lebrun C, Meyer N, Sherman R, Steffen K, and Budgett R. The IOC consensus statement: beyond the female athlete triad-Relative Energy Deficiency in Sport (RED-S). Br J Sports Med 48: 491-497, 2014.

64. Nattiv A, Loucks AB, Manore MM, Sanborn CF, Sundgot-Borgen J, and Warren MP. American College of Sports Medicine position stand. The female athlete triad. Med Sci Sports Exerc 39: 1867-1882, 2007.

65. Nindl BC. Physical Training Strategies for Military Women's Performance Optimization in Combat-Centric Occupations. J Strength Cond Res 29 Suppl 11: S101$106,2015$.

66. Nygaard IE, \& Shaw, J.M. Physical activity and the pelvic floor. Am J Obstet Gynecol: 164-171, 2016.

67. Nygaard IE, Barber, M.D., Burgio, K.L., et al. Prevalence of symptomatic pelvic floor disorders in US women. JAMA 300: 1311-1316, 2008.

68. Obusek JP, Harman EA, Frykman PN, Palmer CJ, and Bills RK. The Relationship of Backpack Center of Mass Location To the Metabolic Cost of Load Carriage 1170. Med Sci Sports Exerc 29: 205, 1997.

69. Orloff HA and Rapp CM. The effects of load carriage on spinal curvature and posture. Spine 29: 1325-1329, 2004.

70. Orr R. The History of the Soldier's Load. Australian Army Journal VII: 67-88, 2010.

71. Orr R, Knapik J, and Pope R. Avoiding Program-Induced Cumulative Overload (PICO). Journal of Special Operations Medicine 16: 61-64, 2016. 
72. Orr R and Moorby GM. The physical conditioning optimisation project - a physical conditioning continuum review of the Army Recruit Training Course. Department of Defence Canberra: AUST, 2006.

73. Orr R, Pope R, Johnston V, and Coyle J. Load carriage: Minimising soldier injuries through physical conditioning-A narrative review. Journal of Military and Veterans' Health 18: 31-38, 2010.

74. Orr RM and Pope R. Gender differences in load carriage injuries of Australian army soldiers. BMC Musculoskelet Disord 17: 488, 2016.

75. Orr RM, Pope R, Coyle J, and Johnston V. Occupational Loads Carried by Australian Soldiers on Military Operations. Journal of Health Safety and the Environment 31: 451$467,2015$.

76. Orr RM, Pope R, Johnston V, and Coyle J. Soldier occupational load carriage: a narrative review of associated injuries. International journal of injury control and safety promotion 21: 388-396, 2014.

77. Patterson MJ, Roberts WS, Lau WM, and Prigg SK. Gender and Physical Training Effects on Soldier Physical Competencies and Physiological Strain. Technical Report 65 Defence Science and Technology Organisation, 2005.

78. Pederson AV, Stokke R, and Mamen A. Effects of extra load position on energy expenditure in treadmill running. Eur J Appl Physiol 102: 27-31, 2007.

79. Plowman S and Smith DL. Exercise physiology for health, fitness, and performance. Philadelphia, PA: Lippincott Williams \& Wilkins, 491, 2007.

80. Polcyn AF, Bensel CK, Harman E, and Obusek JP. The effects of load weight: a summary analysis of maximal performance, physiological and biomechanical results from four studies of load carriage systems. In: RTO Meeting Proceedings 56: Soldier Mobility: Innovations in Load Carriage System Design and Evaluation, Kingston, Canada, 27-29 June 2000. Research and Technology Organisation/North Atlantic Treaty Organization, 2001.

81. Pope R. Prevention of pelvic stress fractures in female army recruits. Mil Med 164: 370373, 1999.

82. Pope R. Prediction and prevention of lower limb injuries and attrition in army recruits. PhD Dissertation Charles Sturt University, 2002, p 286.

83. Rauh MJ, Macera CA, Trone DW, Shaffer RA, and Brodine SK. Epidemiology of stress fracture and lower-extremity overuse injury in female recruits. Med Sci Sports Exerc 38: 1571-1577, 2006.

84. Rauh MJ, Nichols JF, and Barrack MT. Relationships among injury and disordered eating, menstrual dysfunction, and low bone mineral density in high school athletes: a prospective study. Journal of Athletic Training 45: 243-252, 2010.

85. Robertson RJ, Caspersen CJ, Allison TG, Skrinar GS, Abbott RA, and Metz KE. Differentiated perceptions of exertion and energy cost of young women while carrying loads. Eur J Appl Physiol Occup Physiol 49: 69-78, 1982. 
86. Robinson J, Roberts A, Irving S, and Orr R. Aerobic Fitness is of Greater Importance Than Strength and Power in the Load Carriage Performance of Specialist Police. International Journal of Exercise Science 11: 987-998, 2018.

87. Ross RA. Stress fractures in Royal Marine recruits. Mil Med 167: 560-565, 2002.

88. Sargent D and Clarke R. Strength and Conditioning for Female Athletes. Mobility for Performance in Female Athletes. Marlborough:UK Crowood Press Limited 111-139, 2018.

89. Scott PA and Ramabhai L. Load Carrying: in situ Physiological responses of an infantry platoon. Ergonomics 2000: 18 - 24, 2000.

90. Seay JF. Biomechanics of Load Carriage--Historical Perspectives and Recent Insights. $J$ Strength Cond Res 29 Suppl 11: S129-133, 2015.

91. Seay JF, Gregory VA, Frykman PN, Smith NI, and Fellin RE. Spatiotemporal Comparisons Between Male and Female Soldiers While Walking With Heavy Loads: 124 Board\# 5 May 30930 AM-1130 AM. Med Sci Sports Exerc 50: 11, 2018.

92. Shaw JM, Hamad NM, Coleman TJ, Egger MJ, Hsu Y, Hitchcock R, and Nygaard IE. Intra-abdominal pressures during activity in women using an intra-vaginal pressure transducer. J Sports Sci 32: 1176-1185, 2014.

93. Shaw JM and Nygaard IE. Role of chronic exercise on pelvic floor support and function. Current opinion in urology 27: 257-261, 2017.

94. Sheppard C and Waggener A. Women in Combat. Army War College Carlisle Barracks PA, 2007.

95. Steele N and Yoder LH. Military Women's Urinary Patterns Practices, and Complications in Deployment Settings. Urologic Nursing 33, 2013.

96. Stuempfle KJ, Drury DG, and Wilson AL. Effect of load position on physiological and perceptual responses during load carriage with an internal frame backpack. Ergonomics 47: 784-789, 2004.

97. Trego LL and Jordan PJ. Military Women's Attitudes Toward Menstruation and Menstrual Suppression in Relation to the Deployed Environment: Development and Testing of the MWATMS-9 (Short Form). Women's Health Issues, 20: 287-293, 2010.

98. Twombly SE and Schussman LC. Gender differences in injury and illness rates on wilderness backpacking trips. Wilderness \& Environmental Medicine 6: 363-376, 1995.

99. Uustal Fornell E, Wingren G, and Kjolhede P. Factors associated with pelvic floor dysfunction with emphasis on urinary and fecal incontinence and genital prolapse: an epidemiological study. Acta Obstet Gynecol Scand 83: 383-389, 2004.

100. Woodman PJ, Swift SE, O'Boyle AL, Valley MT, Bland DR, Kahn MA, and Schaffer JI. Prevalence of severe pelvic organ prolapse in relation to job description and socioeconomic status: a multicenter cross-sectional study. Int Urogynecol J Pelvic Floor Dysfunct 17: 340-345, 2006. 
This is a non-final version of an article published in final form in: 